\title{
GEOPOLÍTICA E FRONTEIRA OESTE: DIÁLOGOS COM MEIRA MATTOS E COUTO E SILVA
}

\section{GEOPOLITICS AND WEST BORDER: DIALOGUES WITH MEIRA MATTOS AND COUTO E SILVA}

\author{
Jussaramar da-Silva ${ }^{1}$ \\ Pontifícia Universidade Católica de São Paulo, Brasil \\ Nataniél Dal-Moro ${ }^{2}$ \\ Universidade Católica Dom Bosco, Brasil
}

\section{RESUMO}

Carlos de Meira Mattos e Golbery do Couto e Silva são figuras de expressão no Brasil quando o assunto é geopolítica. Este artigo objetiva analisar como estes pensadores e formuladores de projetos, sobretudo à época da Ditadura Civil-Militar brasileira (1964-1985), difundiram suas teorias e quais práticas utilizaram para materializar os seus projetos. Os escritos desses autores, em especial os publicados na forma de livros, serão cotejados. O intuito específico é o de esboçar o pensamento destes formuladores de políticas nacionais a respeito da fronteira oeste do Brasil, bem como quais projetos julgavam imprescindíveis à defesa do território nacional e da Nação brasileira e quais tipos de ações as suas análises efetivaram. Enfim, recuperar aspectos que sinalizam como ficou o oeste brasileiro após a interferência desses estrategistas militares na região.

1 Doutoranda em História Social pela Pontifícia Universidade Católica de São Paulo - Brasil. Integrante do grupo de pesquisa do Centro de Estudos de História da América Latina (CEHAL) da Pontifícia Universidade Católica de São Paulo. Bolsista CAPES. E-mail: jussaramar@gmail.com

2 Pós-Doutor em História do Brasil pela Universidade Nova de Lisboa - Portugal. Pesquisador vinculado ao Núcleo de Estudos de História Social da Cidade (NEHSC) da Pontifícia Universidade Católica de São Paulo - Brasil e ao Programa de Pós-Graduação em Desenvolvimento Local da Universidade Católica Dom Bosco - Brasil. E-mail: natanieldalmoro@bol.com.br

Fecha de recepción: 03 de abril de 2016

Fecha de aceptación: 23 de agosto de 2016 
Jussaramar da-Silva, Nataniél Dal-Moro. Geopolitics and west border: Dialogues

with meira mattos and couto e silva

Palavras-chaves: Brasil, oeste brasileiro, fronteiras, militares, geopolítica

\begin{abstract}
Carlos de Meira Mattos and Golbery do Couto e Silva are expressive figures in Brazil when it comes to geopolitics. This article aims at analyzing how these thinkers and policy-makers, especially at the time of the Brazilian Civil-Military Dictatorship (1964-1985), spread their theories and which practices they used to materialize their projects. The writings of these authors, especially those published in books, will be crosschecked. The specific aim is to understand how these Brazilian policy-makers did not conceive the West border of Brazil, which projects they understood as essential to the defense of the national territory and the Brazilian nation and what kinds of actions their analysis accomplished. Finally, to retrieve aspects signaling the situation of Western Brazil after the interference of these military strategists in the region.
\end{abstract}

Keywords: Brazil, Western Brazil, borders, military, geopolitics

\title{
Introdução
}

Este trabalho procura recuperar uma parcela do pensamento geopolítico que, de algum modo e com muitas especificidades, vigorou na América do Sul e no Brasil em meados do século XX. Daremos destaque às formulações que almejavam adensar a ocupação populacional na Amazônia brasileira, projetando que a sua economia, na verdade um modelo específico de economia, a capitalista, se tornasse mais representativa no âmbito nacional. Não obstante, tal linha de pensamento procurava guarnecer as fronteiras, recorridas vezes descritas como "espaços vazios", sinônimos de locais parcamente ou até inabitados e, também, propensos à invasão.

Em análise retrospectiva, pode-se afirmar que a problemática que se ocupou dos "limites nacionais" data da própria ocupação do território brasileiro pelos povos europeus, em particular os espanhóis e, mais ainda, os portugueses. No final do século XIX, já no período correspondente ao Império, a Guerra da Tríplice Aliança (1864-70), também chamada Guerra contra o Paraguai - para nos atermos tão somente em um exemplo -, dentre outros aspectos, sinalizava a questão da demarcação, ocupação e defesa do Oeste, pois o Estado nacional brasileiro via com preocupação a existência de algumas bordas do território, já que as concebia como fronteiras que ficavam "nos confins do Império" e, mais do que isto, estariam desguarnecidas em caso de ataques.

De forma constante nas décadas seguintes, a problemática continuou sendo discutida no Brasil, como tão bem sinalizam inúmeros registros. Instituída no primeiro governo de Getúlio Vargas (anos 1930), a política 
da campanha chamada Marcha para o Oeste compunha-se de elementos seculares, tentando comprovar e reafirmar a necessidade de ocupação das plagas interioranas, no sentido de garantir efetivamente ao território brasileiro a tão necessária unidade. No entendimento de Alcir Lenharo (1989, p. 69): "Manter o Brasil no original significa portanto caminhar para o sertão e cerrar as portas do litoral à infecção ideológica e sua ação dissolvente."

Este artigo discute o pensamento de dois militares que se detiveram em analisar a referida problemática, propondo diretrizes, planos e projetos para a solidificação do espaço territorial como garantidor da soberania nacional: Golbery do Couto e Silva (1911-1987) e Carlos de Meira Mattos (1913-2007) são as personagens centrais. E mais, a presente reflexão procura articular estas formulações com a premência em transformar o Brasil em uma "potência continental/mundial", seguramente um cartaz dos mais visíveis nos anos 1970, período de acentuado recrudescimento dos regimes ditatoriais nos países do Cone Sul. Dessa maneira, seus pensamentos irão influenciar profundamente uma parte dos integrantes de sua geração, bem como das seguintes. ${ }^{3}$

\section{Geopolíticos e análises geopolíticas}

Golbery do Couto e Silva e Carlos de Meira Mattos atuaram militarmente no campo das letras, elaborando e escrevendo projetos, planos, análises, artigos e livros, e também no mundo da política: interferiram decisivamente no rumo do Brasil pós-1964. Embora já fossem militares de algum relevo antes do golpe militar de 1964, ou, na versão dos partidários e dos apologistas do regime militar, a Revolução de $64^{4}$ - como ficou conhecida a chegada ao poder do executivo federal pelos militares no País -, foi a partir desse ano que o grupo militar conseguiu divulgar e aplicar com mais força as suas ideias (Freitas, 1999). ${ }^{5}$

Golbery pode ser considerado como um dos grandes precursores do pensamento militar moderno no Brasil, sendo que suas análises ganharam notoriedade e força principalmente no pós-golpe. Entretanto, mesmo antes

\footnotetext{
3 Por razões práticas e teóricas, não focalizaremos neste artigo as discussões elaboradas por outros autores.

4 Logo após o golpe, os militares brasileiros intitularam seu movimento de "Revolução", em uma tentativa de promover uma exaltação ao movimento que fizeram, sem assumirem publicamente que se tratou efetivamente de um Golpe de Estado.

5 A obra de Jorge Manuel Costa Freitas (1999) apresenta, dentre outras análises, inúmeros dados biográficos sobre Couto e Silva e Meira Mattos.
} 
de 1964, Golbery publicou Conjuntura política nacional: o poder executivo \& geopolítica do Brasil (Couto e Silva, 1981) 6 , obra que tomaremos como uma referência fundamental, objetivando assim compreender uma parcela das situações advindas com o golpe de 1964, em certo sentido norteadoras da política do Estado brasileiro para se firmar no Cone Sul.

Para compreendermos sua trajetória e sua importância nesse processo de Marcha para o Oeste/interiorização rumo ao Oeste, devemos ter ciência sobre o fato de que Golbery elaborou projetos e esteve no Paraguai por três anos - de março de 1947 até outubro de 1950. Seu pensamento prenunciou e balizou a atuação dos militares, possibilitando meios para que esses chegassem ao poder e, depois, implantassem determinadas políticas. Aliás, o período em que esteve no Paraguai como membro da Missão Militar Brasileira de Instrução no Exército do Paraguai é também o tempo que antecedeu, em poucos anos, o golpe de estado desferido em 1954 por Alfredo Stroessner (1912-2006), lembrando que esse país é limítrofe ao Brasil.

A importância do Golbery do Couto e Silva militar remonta aos estudos realizados sob os auspícios da ESG-Escola Superior de Guerra. Criada em agosto de 1949, a entidade voltava-se "exclusivamente para estudos doutrinários e estratégicos." (Miyamoto, 1985, p. 12). De acordo com Antônio de Arruda (1980), seu objetivo era formar uma elite de pensadores, recrutados entre militares e civis, para que esses atuassem na defesa dos "interesses nacionais". Inclusive, Geopolítica do Brasil, outra obra de Couto e Silva (1967), é constituída de um conjunto de textos apresentados como estudos para essa Escola. Em suas "palavras iniciais", dirigidas aos esguianos, Golbery afirma que

[...] aqui senti, então, a trepidação contagiante da criatividade que inspirava essa Escola, na elaboração de uma Doutrina de Segurança Nacional novinha em folha, autóctone de fato, por mais que em nada alheia ao que se formulava, justo naquele mesmo momento, nos laboratórios estratégicos mais adiantados do mundo (Couto e Silva, 1981, p. 3).

6 Embora a edição usada como referência tenha sido publicada em 1981, nela constam os anos em que o autor escreveu as várias partes do manuscrito original. Em sua primeira parte, os textos se referem ao governo do general do Exército João Figueiredo (1979-85). Já na segunda, foram colocados os textos redigidos ainda da década de 1950, quando o autor pensou a ocupação do território brasileiro e a atuação do Estado. 
Aludindo a essa empreitada, anteriormente o autor afirma ter vivido época muito gratificante em sua vida entre 1952 e 1955, quando pensava e elaborava essa doutrina (Couto e Silva, 1981, p. 3).

Embora nessa obra o autor estivesse se referindo, na parte introdutória, à conjuntura política nacional do período que se passava no governo de João Batista Figueiredo, a parte posterior do material refere-se ao período da primeira metade dos anos de 1950. São conjuntos de estudos desenvolvidos na ESG, pensando a DSN-Doutrina de Segurança Nacional ensejada pelo aporte que o autor tinha em geopolítica, como arte de uma possível guerra que poderia se anunciar. E na DSN, a guerra poderia ser contra o inimigo interno (em particular o povo), ou os inimigos externos (outras nações). Ao mesmo tempo, pensava em elevar o Brasil a uma condição que sobrepujasse as demais, e o ideário da Marcha para o Oeste era um dos pilares para a efetivação deste projeto.

Seguindo a tendência geral, sua Geopolítica do Brasil desenvolve estratégias para que o Brasil aumentasse sua centralização e/ou promovesse algum tipo de desenvolvimento. Essa prática resultaria na ocupação rápida de espaços territoriais, por vezes descritos como "vazios", particularmente nas regiões centrais e, também, em relação às fronteiras do Cone Sul. Buscava-se aprofundar a inter-relação entre as nações, de forma que os "interesses do Brasil" fossem assegurados, sobretudo se ocorressem conflitos, particularmente bélicos. Ao mesmo tempo, Golbery se apoiava nos setores da burguesia industrial, a qual ele considerou fundamental para o desenvolvimento e a integração nacionais:

Mas, no que mais importa, esse desenvolvimento pela industrialização faz prenunciar, afinal, uma libertação mais efetiva em relação aos grandes centros externos, motores do dinamismo econômico mundial, e implicará, em beneficio da unidade e da coesão nacionais, na articulação cada vez mais sólida das diversas porções do amplo domínio, mesmo as mais distantes ou mais excêntricas, a núcleos propulsores radicados no próprio território e, sobretudo, orientados nos genuínos propósitos nacionais (Couto e Silva, 1981, p. 3).

Para esse autor, a burguesia industriária seria o segmento capaz de promover o desenvolvimento, a integração, e mesmo a defesa e a segurança do Brasil. Maria Aparecida de Paula Rago (2008) afirma: José Ermírio 
de Moraes (1900-1973), um dos grandes empresários brasileiros daquele período, e porta-voz de segmentos da burguesia nacional, logo em 1965, denunciava o quanto o Estado nacional brasileiro já se colocava afastado da possibilidade de crescimento desse segmento. Embora haja um jargão nacionalista como pano de fundo, a pauta para Golbery vai se colocar alijando essa burguesia industriária nacional.

Em vários momentos, o autor ponderou que a segurança se colocava como um "paradigma" para as sociedades contemporâneas. O sacrifício da liberdade seria o preço a ser pago, conforme vemos neste fragmento:

[...] a insegurança do cidadão dentro de cada nação e a insegurança de uns Estados em face dos outros, a visão onipresente da guerra - guerra civil ou guerra subversiva ou guerra internacional - dominam o mundo de nossos dias e explicam, por si sós, essa ânsia neurótica com que os indivíduos desamparados, as multidões - em pânico, os povos - desiludidos e aflitos, a Humanidade, enfim, se ergue e se lamenta e se debate, disposta até a escravizar-se a quaisquer senhores e a quaisquer tiranias, desde que lhe ofereçam um prato de lentilhas, um pouco de segurança e de paz. E, assim, acaba ou acabará afinal por perder, com a Liberdade traída, a própria Segurança por que tanto almejara (Couto e Silva, 1981, p. 9).

Conforme exposto anteriormente, apreendem-se alguns dilemas postos pelo autor. Por um lado, o que ele demonstra é que, em nome da segurança, lança-se mão da liberdade. Na perspectiva de Golbery, a liberdade só existia nos países ditos democráticos, ocidentais e cristãos.

Florestan Fernandes (2006) percebeu esses dilemas colocados no Brasil ao longo da formação da burguesia nacional. Segundo ele, esse debate é retomado permanentemente, em especial nos momentos de crise do modelo de desenvolvimento, situação que, às vezes, teria desembocado em ditaduras.

Afora esse aspecto, o que salta aos olhos é a expectativa da segurança como tônica do momento. Pode-se afirmar que o trabalho de Golbery visava convencer parcelas da população letrada e, principalmente, a militar, com as quais suas obras dialogavam, dando o entendimento de que um golpe seria necessário para garantir a segurança e, não menos, um determinado modelo de sociedade. 
Esse fragmento, que por sua vez refere-se ao texto-citação disposto alguns parágrafos antes neste artigo (Conforme informações contidas na obra de Couto e Silva, 1981, p. 9), e do qual lançamos mão é uma espécie de preâmbulo da obra, que vai enunciar a necessidade do controle estatal sobre a sociedade como um todo. Em vários momentos, Golbery recorreu ao Leviatã, texto produzido pelo filósofo Thomas Hobbes, no qual o referido autor explica e detalha a necessidade da mão dura do Estado nacional para gerir a "catástrofe" que era ou que poderia advir do mundo moderno.

Para Golbery, o Brasil deveria ocupar uma posição de destaque, figurando como potência continental. Acreditava ainda em uma possível aliança com os Estados Unidos da América. Assim, é impossível separar as relações que o Brasil desenvolveu na região sem levarmos em consideração as relações diplomáticas e econômicas desempenhadas pelos Estados Unidos dentro do continente.

Para ele, ao lado dessas prerrogativas deveria se acrescentar a defesa da liberdade alicerçada "em sólidas bases [n]a Segurança Nacional." (Couto e Silva, 1981, p. 15). ${ }^{7}$ A ideia da Segurança Nacional já aparecia durante a Era Vargas (1930-1945), também chamada de Período Varguista. Na Lei $\mathrm{n}^{\circ} 38$, promulgada em 04 de abril de 1935, já versava sobre os ditos crimes contra a ordem política e social. Mas não era apenas isso. De acordo com Luciana Grespan Zago (2007, p. 29),

[...] a Doutrina de Segurança Nacional foi posta em prática a partir do momento que se implantou a Ditadura Militar em 1964. Mas dentro da história brasileira as questões relativas à segurança nacional começaram a ser tratadas anteriormente a esse período. Durante o governo de Getúlio Vargas é que se iniciou a implantação das primeiras leis relativas a esse assunto, que não ficaram restritas a manutenção da ordem social. Haviam preocupações com outros setores da sociedade, como a nacionalização do território brasileiro compreendido na fronteira.

7 Pode-se afirmar que nesse período os preceitos da segurança nacional se consolidaram na Doutrina de Segurança Nacional, passando a definir não apenas o inimigo externo (Rússia, China e Cuba), mas também o interno, o qual, ao longo da Ditadura Civil-Militar brasileira, tornou-se o alvo principal da atenção, vigilância, perseguições e repressão. Em outras palavras, o inimigo era o próprio povo, e não potenciais ataques estrangeiros. A respeito dessa situação que se conformou no Brasil, consultar a obra de Maria Helena Moreira Alves (2005). 
Essa perspectiva se aprofundou no período ditatorial iniciado em 1964, justificando e legitimando em certos aspectos o surgimento das áreas delimitadas como de segurança nacional. Além das reservas consideradas estratégicas, capitais, as fronteiras do oeste brasileiro também receberam atenção especial do Estado nacional, em sua grande parte por serem as portas de entrada ou de saída da nação, áreas quase sempre concebidas como vulneráveis, visto que eram ou que poderiam ser pontos de trânsito de indivíduos ou de grupos de inimigos externos e, também, dos internos (Silva, 2013).

Segundo palavras de Couto e Silva (1967), era preciso "tamponar o deserto" "dessa imensa área vazia", pois nesta região - fronteira ocidental do Brasil - "restam nada mais que ilhas esparsas de população - o Mato Grosso de Goiás, Cuiabá, Manaus, as mais importantes - se destacando em meio ao vasto deserto - o enorme espaço vazio da classificação de Supan (menos de 1 h/ $/ \mathrm{km}^{2}$ )." (Couto e Silva, 1967, p. 44 e 43). ${ }^{8}$

Ao fazer a defesa da aliança com os estadunidenses, Golbery não a fez sem um conhecimento prévio do que eram os EUA-Estados Unidos da América. Assim, sua estada naquele País relacionava-se também com sua presença na Itália, como Oficial de Informações, da FEB-Força Expedicionária Brasileira, em 1944. De acordo com Oliveira apud Vânia Noeli Ferreira de Assunção (1999, p. 40):

Muitos oficiais da FEB regressaram ao Brasil convictos da necessidade de acelerar o desenvolvimento econômico. Do ponto de vista militar, significaria promover o desenvolvimento da economia - abrindo-a inteiramente ao capital estrangeiro, se necessário - como condição para o desenvolvimento do próprio aparelho militar com vistas ao papel que o Brasil deveria desempenhar na defesa hemisférica.

Mesmo relevando o ufanismo de Golbery, ou seja, sua pretensão de que o Brasil era melhor do que boa parte do mundo, de que era capaz de elevar-se à categoria de potência mundial, parece não haver dúvida de que a ocupação do Brasil como nação continental na América do Sul, afora a sua relação de subserviência com a política dos EUA, provocou o desfecho de outras relações de dependência, sobretudo de ordens econômicas

8 Em texto clássico na historiografia brasileira, Alcir Lenharo (1985) mostra que não existiam propriamente terras "sem donos", "espaços vazios" e "vazios territoriais e populacionais" no oeste do Brasil, pois as populações sertanejas e, mais ainda, os indígenas nunca se fizeram ausentes deste território. 
e políticas, as quais também produziram implicações de cunhos sociais e humanos de grandes magnitudes ao povo brasileiro.

Em seu livro, encontramos mapas que esboçam o Brasil por meio de uma perspectiva central. E neles, vemos a preocupação do autor em definir melhor a relação com os Estados Unidos, uma vez que os soviéticos, ou até mesmo os chineses, poderiam tentar invadir o Brasil, processo que o tornaria palco de disputas com os Estados Unidos.

Mapa 1. Centros de poder sul-americanos.

\section{ESQUEMA 10}

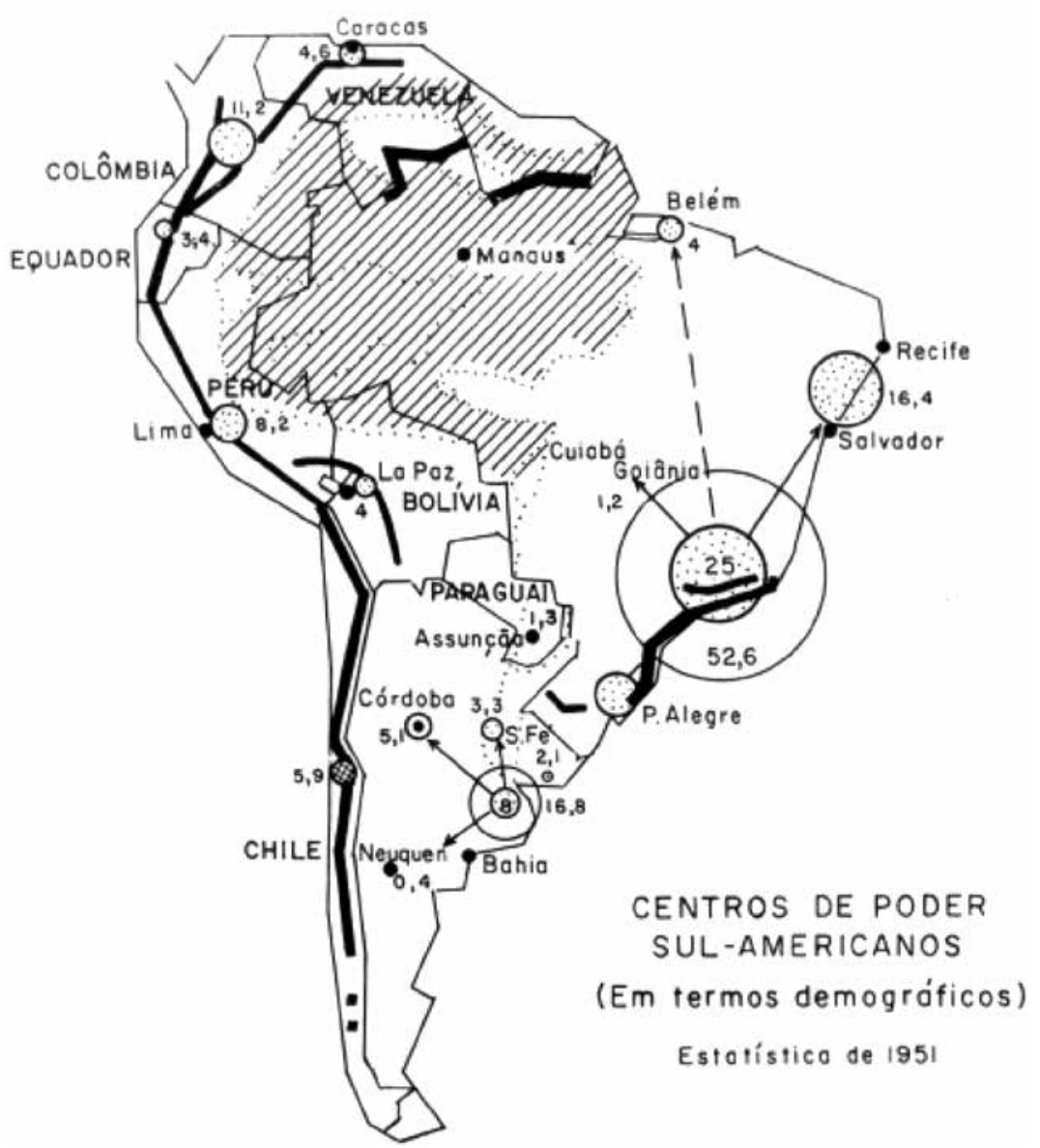

Fonte: Couto e Silva (1981, p. 54). 
Conforme demonstra o mapa acima - imagem que foi publicada em obra de Couto e Silva (1981, p. 54), o Brasil ocupa uma posição central na América do Sul. Ao explicar a importância geopolítica da região Amazônica, Golbery tinha em mente os conflitos ocorridos na região do Chaco, durante os anos de 1930, situação que teria provocado uma Guerra de disputas da região entre Paraguai e Bolívia, lembrando que esta última foi financiada pela Standard Oil.

Com bases nas análises do militar Golbery, vemos que a região Amazônica também estaria conectada ao Chaco, que por sua vez estava próxima da região Centro-Oeste do Brasil/Planalto Central brasileiro, vizinha ao local do conflito durante os anos de 1930. Temia-se que os reveses diplomáticos e bélicos promovidos pelas nações vizinhas prejudicassem de alguma forma o Brasil e, mais ainda, essa região brasileira. Nas palavras de Couto e Silva (1981, p. 55),

[...] a eclosão súbita de um conflito ou o desencadeamento de um ataque, pelo menos sem que sejamos alertados com grande antecedência por uma sensibilização paulatina das fronteiras, um aumento progressivo da pressão exterior e uma sucessão de incidentes que prenunciem a borrasca - algo assim como o que se passou no Chaco, onde choques intermináveis pela posse dos chamados fortins precederam largamente a deflagração real da luta.

Por esse motivo, o autor defendeu o alinhamento, conforme vemos:

[...] em tais circunstâncias, quando entre nossos vizinhos hispano-americanos recrudesce indisfarçável uma oposição aos Estados Unidos da América que se mascara de Terceira Posição ou que outro rótulo tenha, aproveitando-se exatamente daquela enfocação para além Atlântico e além Pacífico dos interesses primaciais dos norte-americanos, o Brasil parece estar em condições superiores, pela sua economia não competitiva, pela sua larga e comprovada tradição de amizade e, sobretudo pelos trunfos de que dispõe para uma barganha leal - o manganês, as areias monazíticas, a posição estratégica do Nordeste e da embocadura amazônica com seu tampão da Marajó - de negociar uma aliança bilateral mais expressiva que não só nos assegure os recursos necessários para concorrermos substancialmente na segurança do Atlântico Sul e defendermos, se for o caso, aquelas áreas brasileiras tão expostas a ameaças extracontinentais, contra um ataque envolvente ao território via Dacar-Brasil-Antilhas, mas uma aliança que, por outro lado, traduza 
o reconhecimento da real estatura do Brasil nessa parte do Oceano Atlântico, posto um termo final a qualquer política bifronte e acomodatícia em relação a nosso país e à Argentina, ambas nações, por exemplo, igualmente aquinhoadas, contra todas as razões e todas as evidências, em armas de guerra naval (Grifos do original) (Couto e Silva, 1981, p. 50-51).

Este fragmento evidencia vários nexos constitutivos entre os Estados Unidos, Brasil, Paraguai e Argentina. Fica novamente externada a ideia do Brasil como nação hegemônica no Cone Sul; desnuda uma possível posição independente no governo de Isabelita Perón ao falar da "Terceira Posição", que não era nem a favor dos EUA e tampouco da URSS-União das Repúblicas Socialistas Soviéticas, mas que poderia negociar com ambas; evidencia uma possível acomodação do Paraguai, propondo-lhe que assumisse uma postura que pendesse definitivamente para o Brasil e, por fim, seu reflexo durante a Segunda Guerra Fria (a partir dos anos 1970) ${ }^{9}$ foi os Estados Unidos passarem a colaborar mais diretamente com a política e a economia do Estado nacional brasileiro. Ao entendermos detalhadamente a preocupação geográfica, conseguimos compreender como esta política se desenvolveu.

A ideia de uma organização comunista internacional que agiria no Brasil, ou por invasão ou principalmente por infiltração, já se punha desde os anos de 1950. No cenário mundial, "o Ocidente capitalista sentia estar perdendo terreno para as economias comunistas, que haviam crescido mais rapidamente na década de 1950.” (Hobsbawm, 1995, p. 240). Após esse período, essa preocupação foi se agravando. Ao escrever Geopolítica do Brasil, Golbery já demonstrava o que estava por vir nos anos da Ditadura, ou, no mínimo, sinaliza as discussões de uma parte dos militares que depois assumiram o poder. Segundo Paulo Fagundes Vizentini (2003, p. 32), com a

[...] radicalização político-social interna que marcou a crise do populismo, combinada com a busca da autonomia brasileira em relação aos Estados Unidos, justamente no momento que esse país procurava conter o desgaste da sua hegemonia mundial, criou uma situação insustentável para o regime brasileiro e sua diplomacia. Foi o momento do contra-ataque do projeto da ESG [Escola Superior de Guerra]. O alinhamento automático com

9 A Guerra Fria (1945-1991) também ficou conhecida como Paz Fria. A segunda fase da Guerra Fria teria surgido no início da década de 1970 e perdurado até os anos 1980. Segundo Hobsbawm (1995, p. 226 e 241), trata-se de um período de "grande mudança na economia mundial". 
Washington, efetuado pela Doutrina de Segurança Nacional após 1964, combinou-se com a contenção do movimento popular e das tendências 'esquerdistas' da estratégia anterior.

Nesse contexto, as relações com os Estados Unidos, o grande irmão que coadunava com os ideais ocidentais e cristãos, como bem nos informa Stansfield Turner (2008), se cristalizavam com a neurose da Guerra Fria iniciada ainda nos anos 40. No mesmo período os EUA haviam conformado a sua Lei de Segurança Nacional - 1947. Nas palavras de Eric Hobsbawm (1995, p. 224): "Gerações inteiras se criaram à sombra de batalhas nucleares globais que, acreditava-se firmemente, podiam estourar a qualquer momento, e devastar a humanidade. [...] Não aconteceu, mas por cerca de quarenta anos pareceu uma possibilidade diária."

Concomitantemente a isso, no âmbito internacional as agências de Segurança americanas - a exemplo da própria CIA-Agência Central de Inteligência e também do FBI-Agência Federal de Investigação, visto que iniciaram e/ou tiveram remodeladas as suas atividades nos anos 1940, sobremaneira no governo de Roosevelt (1933-45), se voltaram para estabelecer parcerias no mundo todo, deslocando contingentes e recursos, bem como firmando convênios de cooperação internacional, prática que lhes valeria a hegemonia em grande parte do mundo, conforme podemos constatar nas obras de Antonio Pedro Tota (2000) e Stansfield Turner (2008).

Programas policiais foram elaborados e efetivados no Brasil. O governo dos EUA forneceu treinamento e todo um arsenal foi colocado à disposição do governo brasileiro. Golbery do Couto e Silva (1967, p. 254), mesmo pensando o Brasil em seus projetos geopolíticos como uma potência mundial, não desconsidera a importância das nações capitalistas e desenvolvidas do mundo ocidental. Segundo suas palavras:

[...] o Brasil essencialmente depende - e quanto! - do restante do Ocidente e, em particular dos E.U.A., para o seu comércio, o seu desenvolvimento econômico, o seu progresso técnico e cultural, até para a sua própria segurança é fato que para nós, brasileiros de hoje, não exige discussão maior.

A forma estabelecida para esse modelo pode ser vista neste pequeno fragmento: 
Como instituição, a ESG encorajou dentro das forças armadas normas de desenvolvimento associado a valores empresariais, ou seja, um crescimento cujo curso industrial foi traçado por multinacionais e um Estado guiado por razões técnicas e não políticas (Dreifuss apud Assunção, 1999, p. 55).

O Brasil careceria também da tão propalada "interiorização econômica", algo que os militares se propunham a fazer, tendo em vista que os governos anteriores, no entendimento de boa parcela dos militares, não tinham feito: planos e ações a contento da grandeza territorial do País. A interiorização do progresso e do desenvolvimento teria de se dar em dois sentidos: interiorização para o Oeste e interiorização para o grande interior. Para tanto, deveriam ser criados "novos pólos de germinação e do desdobramento dos núcleos dinâmicos já existentes." (Couto e Silva, 1969, p. 3). A Zona Franca de Manaus, edificada no final da década de 1960, seria um exemplo.

Segundo externou Couto e Silva (1969, p. 4), só haveria interiorização na prática se o Brasil resolvesse os problemas de transporte, de telecomunicações e de rede de crédito. Caberia ainda sanar a parca densidade populacional e reverter o baixo nível de qualificação dos trabalhadores.

Quanto ao general Carlos de Meira Mattos, suas ideias são tributárias das obras de autores estrangeiros, como Friedrich Ratzel e Rudolf Kjellén, e dos brasileiros Alberto Torres, Delgado de Carvalho, Mário Travassos, Everardo Backheuser e Lysias Rodrigues. Fazem parte, assim como as análises e os textos de Couto e Silva, do terceiro e quarto períodos dos escritos de geopolítica brasileira, tendo sido formulados sobremaneira no final da década de 1940. Seus pensamentos também adentraram a Escola Superior de Guerra, a qual objetivaria a formação de uma "elite nacional" no campo da segurança e do desenvolvimento nacionais (Miyamoto, 1984, p. 11; Miyamoto, 1995, p. 44).

Carlos de Meira Mattos (2002, p. 17) entendia a Geopolítica como "o produto da evolução da observação gradual da ação do homem na exploração do meio natural." Os seus primeiros escritos foram publicados nos anos 1950. Essa produção esquadrinharia a Política, a Geografia e a História (e estas seriam formadoras da Geopolítica), fornecendo futuros elementos de análise para a manutenção dos espaços existentes e a conquista de outros. 
A "Geopolítica pertence ao grupo das ciências sociais e nós a posicionaríamos como um ramo da política - aquele que trata da aplicação da política aos espaços geográficos." (Meira Mattos, 1990, p. 18.). Nos textos de Meira Mattos, tais como: Brasil, geopolitica e destino, A geopolítica e as projeções do poder, Uma geopolítica pan-amazônica, Geopolítica e teoria das fronteiras e Geopolítica e modernidade: a geopolítica brasilei$r a$, há sempre uma preocupação em projetar o Brasil no cenário mundial. Fazia-se necessária também a transformação do País em uma nação de importância global, portanto não mais restrita ao âmbito regional..$^{10} \mathrm{Nas}$ palavras de Meira Mattos (2002, p. 75):

Em 1959, publicamos o nosso primeiro trabalho sobre geopolítica, um fascículo de 72 páginas que denominamos Projeção Mundial do Brasil, numa sugestão de que o Brasil já podia almejar uma escalada de poder, trinta anos depois do Projeção Continental de Travassos. Na apresentação deste livro escrevemos: "O capitão de 1931 sonhou com um Brasil potência continental. Nós lhe pedimos licença para sonhar agora com um Brasil potência mundial."

A "busca do progresso" dava-se quando o "homem" dominava a "natureza física", mais especificamente o solo, a terra (Meira Mattos, 1990, p. 11). Embora não desconsidere a necessidade de o Brasil estar militarmente presente nas áreas marítimas e nas aéreas, o general Meira Mattos deixa sobressaltar nos seus escritos a importância da efetiva ocupação da área terrestre sobre as demais.

Segundo Meira Mattos (1977, p. 110-111), os governos militares deveriam, a todo custo, realizar a tão necessária "continentalização da hinterlândia sul-americana". Esse plano daria um "sopro de despertar" na "América do Sul continental". Para tanto, determinadas tecnologias e estratégias, como as formuladas na ESG, eram indispensáveis no sentido de ocupar populacional e economicamente duas áreas em especial: a Bacia Amazônica (Região Norte do Brasil) e o Centro do Continente (Região Centro-Oeste).

Ao entender a constituição do território brasileiro como sendo fruto de quatro fases, a saber: fase de expansão; fase de regularização; fase de

10 Boa parte destas obras se tornou acessível para o grande público via publicações da Biblioteca do Exército (BIBLIEX). 
demarcação e fase de vivificação ou povoamento, Meira Mattos propunha como projeto geopolítico vital para o Brasil nas décadas de 1960-70 o desenvolvimento e a ocupação da fronteira ocidental do País, em particular das terras amazônicas. As premissas básicas eram: Segurança \& Desenvolvimento (Meira Mattos, 1990, p. 65). Ademais, a efetivação do plano de continentalização da América do Sul abrangeria, assim afirma Meira Mattos (1990, p. 110), "enormes regiões interiores de nove países fraternos e vizinhos, mas que nunca souberam dar-se as mãos pelas portas das conexões terrestres de seus territórios, que mal conheciam, escravos que eram da via marítima para se comunicarem." 11

Poderíamos compreender parte das reflexões de Meira Mattos (1977, p. 82) como um discurso técnico, oficial e político chancelado por instituições governamentais. O período imediatamente anterior a 1964 foi descrito como "três anos de insânia que em 1961, 1962, 1963 e começo de 1964 envolveram a nação." Seriam "anos críticos". Referindo-se provavelmente aos governos dos presidentes Jânio Quadros (janeiro/1961-agosto/1961) e, particularmente, João Goulart (setembro/1961-abril/1964), porém sem mencioná-los de forma literal em sua obra, diz-nos que os militares teriam recebido um Brasil "que mais parecia "uma massa falida", arrasada por três anos de demagogia e de irresponsabilidade administrativa [...]."

Ainda que composto por várias linhas de pensamento, o projeto iniciado com a Revolução de 64 visava, em linhas gerais, enaltecer a chegada e os feitos executados pelos militares entre os anos 1960-70, bem como propagandear projetos futuros de um Brasil que se queria potência mundial. Meira Mattos (1977, p. 82-83) afirma que o general "Castelo Branco teve [...] o grande mérito de, chegando ao Palácio do Planalto, aplicar a metodologia da ESG no equacionamento de nossa política."

Interessa-nos aqui sobremaneira a proposta de um modelo de interiorização do progresso e do desenvolvimento ${ }^{12}$ sobre o Brasil interno, prática que beneficiaria a todos, inclusive aos povos dos países limítrofes ao território nacional brasileiro. "A transformação dessas regiões interiores

11 Determinados indícios sugerem que os nove países vizinhos seriam: Bolívia, Colômbia, Equador, Guiana, Guiana Francesa, Paraguai, Peru, Suriname e Venezuela. Meira Mattos (1977, p. 90) dizia que o Brasil tinha "contatos fronteiriços muito tênues com os nossos vizinhos continentais do norte e noroeste".

12 Grosso modo, os sentidos das palavras progresso e desenvolvimento podem ser pensados como sinônimos. Indicavam basicamente acréscimo populacional, expansão da infraestrutura, sobretudo construção de rodovias, militarização estatal, intensificação comercial e, sobretudo, implantação e consolidação da economia em áreas concebidas como despovoadas do interior brasileiro. 
em áreas de intercâmbio internacional, atraindo para elas transportes, comunicações, população, serviços públicos, representará um "toque de alvorada" não somente no Brasil mas em todos os nossos vizinhos." (Meira Mattos, 1977, p. 16).

O objetivo central residia em reverter a suposta posição de isolamento que assolaria o interior brasileiro - e a Amazônia brasileira em especial - quando comparada às demais áreas do território nacional. Visando a efetivação dessa política, assim nos informa Meira Mattos (1990), transferiu-se a capital federal do Rio de Janeiro para a cidade de Brasília, foram construídas estradas, usinas de geração de energia, armazéns, núcleos de povoamento, vilas agrícolas, indústrias de beneficiamento de grãos, dentre outras ações. Intensificou-se também a militarização da região. O avanço da fronteira agrícola sobre as terras do Cerrado extrapolou os limites nacionais, estendendo-se ainda para os territórios paraguaio e boliviano. Consequentemente, o poder geopolítico brasileiro também foi ampliado.

Meira Mattos (1977, p. 84) concebeu nos seguintes termos o trabalho realizado pelos militares: "Através de quatro presidentes revolucionários foi possível manter-se uma invejável continuidade na busca de objetivos nacionais, na orientação dos planos básicos e no fortalecimento do poder."'13

Planos e produções cartográficas também são itens frequentes nos trabalhos de Meira Mattos. Constatamos que os últimos estão pulverizados em muitos capítulos de suas obras. Analisando os textos em geral e os mapas em particular produzidos e/ou utilizados por Meira Mattos - a exemplo dos capítulos XIII e IX da obra $A$ geopolítica e as projeções do poder e Geopolítica e modernidade: a geopolítica brasileira - visualizamos o que seria a atuação do Estado nacional sobre as terras amazônicas: muito claramente um interior a ser integrado ao restante do Brasil e conectado ao mundo. Por sua vez, essa ação não seria possível sem a incorporação das terras da Região Centro-Oeste e, mais ainda, do Estado de Mato Grosso, integrante do Centro do Continente, ao mesmo projeto geopolítico. ${ }^{14}$

13 Meira Mattos referia-se aos governos dos generais-presidentes Castelo Branco, Costa e Silva, Médici e Geisel.

14 O Estado de Mato Grosso era conhecido, dentre outras denominações, como o "Grande Estado do Brasil Central" e abarcava os territórios que hoje compõem os Estados de Rondônia, Mato Grosso do Sul e Mato Grosso. Era igualmente descrito como uma região "pouco povoada" e que precisaria ser "desenvolvida". A densidade populacional na década de 1940 era menor do que a do Estado do Amazonas. As terras matogrossenses abarcavam parte das três mais expressivas áreas geopolíticas do Brasil, com destaque para a Bacia Amazônica, a Bacia do Prata e o Centro do Continente. Ver outros detalhes em Moro (2014). 
Mapa 2. Áreas interiores de intercâmbio.

\section{ÁREAS INTERIORES DE INTERCÂMBIO FRONTEIRIÇO E SISTEMA RODOVIÁRIO PLANEJADO PARA A VERTEBRAÇÃO DA PAN-AMAZÔNIA}

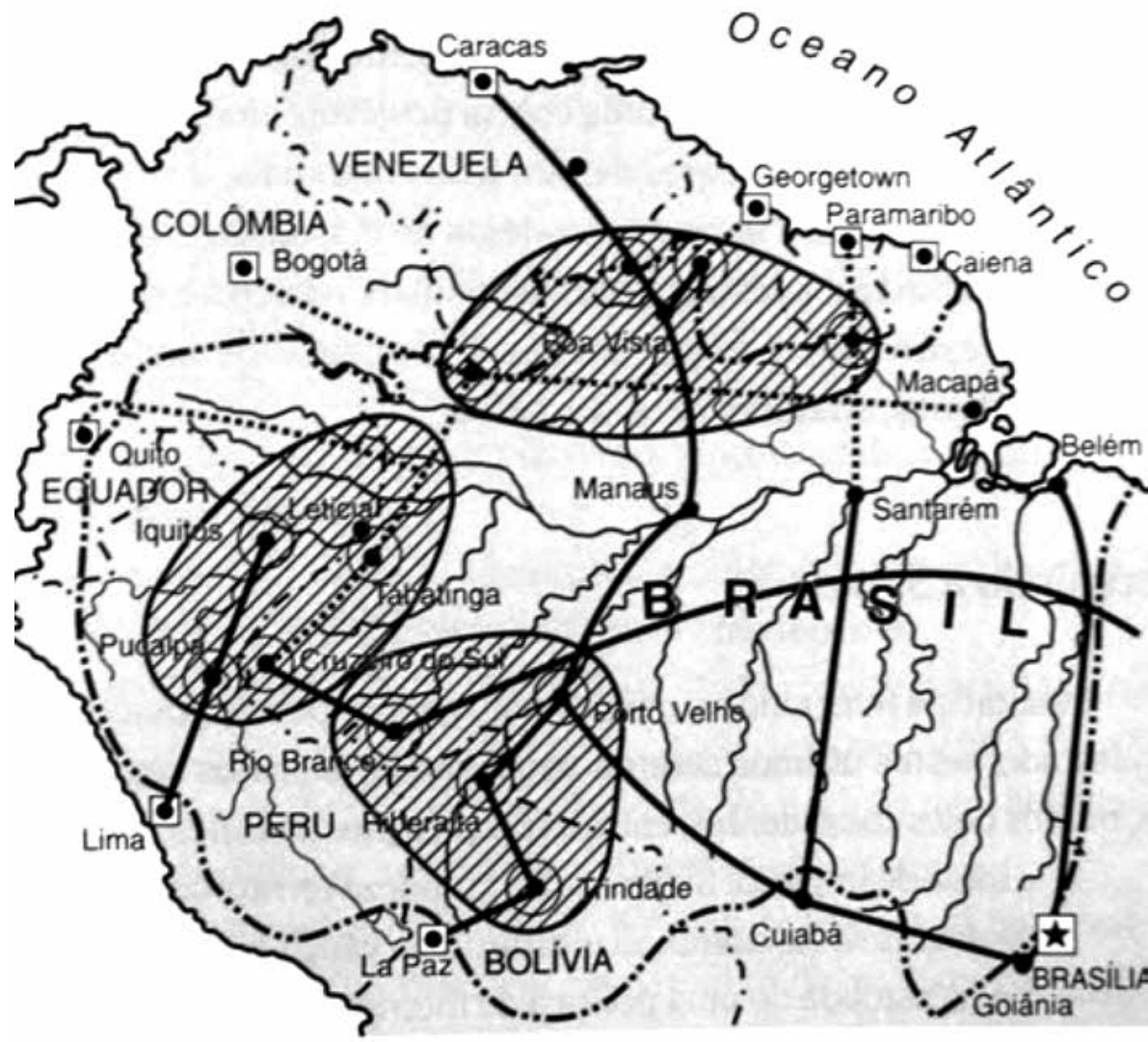

Existente -

Planejada -

Fonte: Meira Mattos (2002, p. 89). 
Na prática, a Amazônica não foi brindada com o desenvolvimento e a ocupação teorizadas nas análises de autores como Couto e Silva e Meira Mattos. O tão almejado progresso, sobretudo no viés de uma interiorização nacional que teria ramificações com as nações vizinhas, podendo integrar e amalgamar o território, tal qual entendiam estes militares nos anos 1950-70, ocorreu apenas de forma parcial. Inclusive, alguns estudos - a exemplo do que constatamos no artigo de Gerd Kohlhepp (2002) - mostram vivamente que o lado negativo desse projeto-ação foi mais enfático do que o positivo. Entretanto, as terras do Estado de Mato Grosso foram ocupadas com muito mais "sucesso", do ponto de vista geopolítico, do que as da fronteira amazônica.

Povoou-se a região com o "elemento branco", ou ao menos "embranquecido", fato que resultou no adensamento do número de habitantes por $\mathrm{km}^{2}$. Foram construídas vias de comunicação com o propósito de facilitar as atividades de transportes de grãos, mercadorias e pessoas. Houve também a feitura de projetos diversos e o desenvolvimento de algumas atividades econômicas, sobretudo na agricultura monocultora, em particular nas culturas do milho e da soja, esperando que essas gerassem dividendos ao Brasil.

\section{Atuações militares na fronteira oeste do Brasil}

Os projetos de desenvolvimento dados pelos imperativos do capitalismo internacional e sua necessidade de geração de energia, de desenvolvimento para atender suas demandas, acabou por gestar obras como a construção de barragens hidrelétricas (Silva, 2010). Assim, para intervir e concentrar a dinâmica do desenvolvimento do parque tecnológico no Brasil, os militares também iniciaram a ocupação do interior através da chamada "política dos corredores de exportação", projeto esboçado na década de 1930, porém materializado somente nos anos 1960. Segundo Nelson Bacic Olic (1994, p. 49-52) e Shiguenoli Miyamoto (1995), essa política deslocou o Paraguai da área de influência argentina via Bacia do Prata. Tal prática contribuiu para que ele ficasse mais próximo do Brasil a partir da segunda metade do século XX.

Data desse período a construção de empresas como Itaipu e Tucuruí, para a geração de energia; construção de pontes, como a Rio-Niterói, e a Ponte da Amizade com o Paraguai; estradas como a Transamazônica, incentivo à migração nas áreas Norte e Centro-Oeste, com destaque para 
as terras de cerrado, inclusive amparadas nessas obras; iniciativas como o Projeto Rondon, para que se tivesse melhor dimensão dos "problemas sociais" do interior, mas, principalmente, para que o Estado conseguisse controlar as populações que viviam "desgarradas" dos grandes centros e vulneráveis à atuação do que eles chamavam de ideias "alienígenas", conjunto de valores e práticas que poderiam ser traduzidas e albergadas, vulgarmente, na palavra comunismo.

Por meio de suas obras, o sociólogo Octavio Ianni oferece-nos uma análise emblemática deste processo de "desenvolvimento nacional". Dentre outras questões, o referido autor mostra os problemas e a precariedade da infraestrutura disposta à população empobrecida que vivia nesses confins da nação brasileira e, sobretudo, as dificuldades enfrentadas pelos sujeitos ao migrarem para as plagas amazônicas em busca de um pedaço de terra. Paralelamente Ianni (1979) descortina e nos chama a atenção para os ganhos financeiros obtidos por alguns grupos da elite nacional e instituições multinacionais que passaram a atuar na região, quase sempre obtendo significativos ganhos. Essa ação ajudou a preparar ainda mais o terreno para a consolidação do capitalismo agroexportador nessas terras. ${ }^{15}$

A penetração do Brasil no continente sul-americano pode também ser lida e explicada à luz da conivência dos EUA. De acordo com Domingos Laino (1979, p. 12), a divisão de linhas fez-se da seguinte forma:

Duas correntes teóricas traçam o marco geopolítico da ação do governo brasileiro: a primeira corresponde ao tenente-coronel Mário Travassos e logo a de seu continuador, o general Golbery do Couto e Silva. Segundo Juan E. Guglialmelli a problemática geopolítica do Brasil na América Latina, com ênfase no antagonismo entre as bacias do Amazonas e do Prata [percebe-se n] a oposição entre ambas as bacias [e] resolveria-se em torno do controle e atração do 'triângulo econômico' Cochabamba-Sucre-Santa Cruz. Afirma Travassos que 'o Brasil da Bacia do Prata, apesar de requerer meios artificiais para unir-se ao oceano, dispõe de portos com suficiente capacidade de atração na costa e dos estímulos de dois países mediterrâneos que naturalmente reagem contra a força centrípeta do Prata: o Sul do Mato Grosso, prolongando os territórios de São Paulo e Paraná, representa a força de penetração'.

15 A respeito da referida problemática, sugerimos a leitura dos seguintes textos de Octavio Ianni, todos publicados em 1979: A luta pela terra, Colonização e contra-reforma agrária na Amazônia e Ditadura e agricultura. 
Acreditamos que a consolidação do Brasil na fronteira oeste pode ser aferida por dois fragmentos de Couto e Silva. Estas reflexões estão distantes duas páginas uma do outra, constituintes de um item denominado Diretrizes Geopolíticas, e que comprovam que uma alternativa como a de Itaipu foi pensada na perspectiva de dominação da região. Referindo-se ao rio Paraguai: "a incorporação, também, da periferia circulatória do segundo cinturão interior onde ressalta o papel integrador do Paraguai e seus maiores afluentes" (Couto e Silva (1981, p. 132-3). Na sequência, Couto e Silva (1981, p. 135) afirmou:

Importa salientar, pelo menos, a importância da vitalização dos rios navegáveis de toda a faixa fronteiriça onde a bandeira brasileira precisa, no mais curto prazo, fazer-se não só presente, mas assídua, e, além disso, a necessidade de um concurso nacional, de fato representativo, nas ligações tanto aéreas como também marítimas, entre os principais centros populosos dos países sul-americanos.

O que se apresenta em Geopolítica do Brasil é bastante clarificador da ação militar. Nas conclusões do texto de 1960, Couto e Silva (1981, p. 137-138) expõe que a geopolítica brasileira deve pautar-se, dentre outros aspectos, por "expansionismo para o interior e, também, de projeção pacífica no exterior"; ao mesmo tempo em que se faça uma "geopolítica de contenção, ao longo das linhas fronteiriças" e, por fim, geopolítica de "participação na defesa da Civilização Ocidental, que também é a nossa."

As análises de Meira Mattos mostram-se essencialmente próximas da referida questão. Esse autor cita em várias oportunidades a obra do general Golbery, ao que tudo indica com o intuito de reafirmar os seus pensamentos geopolíticos. O grande projeto, em síntese, dos generais em estudo neste artigo foi transformar o Brasil em uma potência mundial. Em 1980, mesmo um lustro antes de findada a Ditadura Civil-Militar brasileira (1964-85), Meira Mattos admitia literalmente que a concretização dos projetos geopolíticos de povoamento e de colonização efetivas do interior do Brasil ainda estavam inconclusos. Em outras palavras, e aqui nos valemos das reflexões externadas por Silvana de Abreu (2001), poderíamos dizer que o Plano de Viação Nacional (1973), as obras rodoviárias, o PIN-Programa de Integração Nacional (1973), o Programa de Pólos Agropecuários 
e Agrominerais da Amazônia (1975), dentre outros, não atingiram os objetivos esperados.

"Assim, em termos de estratégia de ocupação de vastos espaços vazios, estamos diante de duas experiências inacabadas. Nem o ambicioso Programa de Integração Nacional, governo do Presidente Médici, na parte de colonização pôde ser cumprido, nem o Programa Poloamazônia do governo Presidente Geisel terminou de ser implementado." (Meira Mattos, 1980, p. 101).

Em conformidade com a citação anterior, a Amazônia continuava afastada do território nacional - entenda-se aqui o leste/litoral brasileiro. Estaria ainda parcamente povoada e com uma produção econômica inexpressiva quando comparada à totalidade do Produto Interno Bruto produzido no Brasil. Mesmo assim, a "Modernização conservadora "de cima", exercida pelos governos militares que incorporavam o setor privado às elites regionais e nacionais por incentivos fiscais, tinha que manter a aparência democrática de modo a não colocar em perigo os créditos internacionais." (Kohlhepp, 2002, p. 40).

No Estado de Mato Grosso, entendido aqui como "Grande Estado do Brasil Central", pode-se afirmar que ocorreram transformações geopolíticas mais expressivas do que as verificadas nas terras amazônicas. A migração de agricultores e de pessoas comuns provenientes de todos os locais do Brasil foi muito intensa nas décadas de 1960 e, sobretudo, no decorrer dos anos 1970-80. Municípios como Campo Grande e Dourados, hoje pertencentes ao Estado de Mato Grosso do Sul (MS) ${ }^{16}$, tiveram os seus cotidianos alterados em razão deste processo de avanço da fronteira agrícola (Moro, 2009).

Por meio do desenvolvimento da monocultura de grãos, o solo oestino passou a ser valorizado financeiramente e a região, que na década de 1920 chegou a ser pensada como "cerrado estéril" (Amaral, 1927, p. 12-13), tornou-se uma fronteira agrícola de grande relevo não apenas para o Brasil potência continental/mundial. Pensando no êxito dos projetos geopolíticos das décadas de 1960 e, sobretudo, da de 1970, poderíamos

16 Mato Grosso do Sul foi criado no dia 11 de outubro de 1977, passando a existir efetivamente em janeiro de 1979. Antes, a referida região integrava a parcela sul do então Estado de Mato Grosso. Após a divisão, o norte continuou sendo denominado como Estado de Mato Grosso, e sua capital permaneceu em Cuiabá. A porção sul do território da antiga Unidade Federativa de Mato Grosso tornou-se Estado de Mato Grosso do Sul. A cidade de Campo Grande foi alçada ao posto de capital política e administrativa. 
afirmar que as terras do Centro do Continente, em particular as do Planalto Central, foram "ocupadas" bem mais a contento do que as terras da Bacia Amazônica. Contudo, essa realidade não foi projetada tão nitidamente nos escritos geopolíticos destes generais. Também não podemos desconsiderar os efeitos negativos ou, no mínimo, limitados que assolaram a região, acometendo as populações nativas e, ainda, determinados grupos de migrantes. Os estudos de Alexandre Panosso Netto (2002) e de Vitale Joanoni Neto (2007) recuperam uma parte desse processo.

Esse fato sinaliza, por um lado, a não concretização dos projetos geopolíticos ao tentarem construir um Brasil potência mundial, pois na teoria o interior precisaria ser povoado para então tornar-se economicamente ativo e integrado no conjunto nacional; por outro, mostra a dependência política desse mesmo Brasil potência mundial diante dos demais países capitalistas do mundo ocidental, uma vez que a tão alardeada ocupação econômica do oeste brasileiro - ou em outros termos da fronteira ocidental/fronteira oeste - fez-se na prática muito mais pela exigência desse mundo industrializado e desenvolvido do que em razão dos empenhos e das ações geopolíticas pensadas e defendidas por determinados grupos sociais vigentes no Brasil dos anos 1950-70.

\section{Considerações finais}

Os escritos de Golbery do Couto e Silva e de Carlos de Meira Mattos são datados e indicam a existência, tanto no Brasil quanto na América do Sul, de autores, de grupos sociais e de políticas governamentais amplamente apoiadas pelo Estado brasileiro entre as décadas de 1950-70 que procuraram fomentar um modelo de desenvolvimento nacional ancorado em alguns pressupostos da geopolítica desenvolvida na ESG. Esse modelo poderia ser concretizado se os países seguissem algumas metas, dentre as quais merecem destaque: a) defesa dos limites territoriais interiores julgados como menos protegidos e b) ocupação populacional dos chamados "espaços vazios". Por sua vez, a transformação dessas estratégias em realidade geraria um desenvolvimento econômico regional/nacional, beneficiando a nação como um todo e, também, os países vizinhos. A continentalização do interior da América do Sul, sobretudo estratégica e econômica, seria o benefício mais destacado desse plano geopolítico.

A realidade nos mostra que entre a teoria e a prática, os planos e o mundo concreto, as distâncias podem e, de fato, foram imensas. Situação 
de certa forma também reconhecida textualmente pelos autores geopolíticos aqui estudados, a exemplo de uma afirmação do próprio Carlos de Meira Mattos (1980, p. 101). A efetivação dos projetos geopolíticos na região da fronteira oeste brasileira indica que, em muitos casos, consideráveis contingentes populacionais foram fixados em áreas desprovidas da mais básica infraestrutura. As condições de acesso e de sobrevivência também eram deficitárias. A tentativa de preenchimento dos "espaços vazios" ou dos "vazios demográficos" ocorreu atendendo à conveniência do capital nacional que, não poucas vezes, só logrou êxito ao associar-se a grupos internacionais. Inúmeros indícios textuais contidos nas obras geopolíticas de Golbery do Couto e Silva e Carlos de Meira Matos nos mostram que as necessidades humanas não eram propriamente o cerne das preocupações desses autores. Esperava-se que os fatores estratégicos e econômicos resolvessem todos os demais "problemas".

Outro aspecto importante foi o de que a "colonização" das fronteiras atendeu em grande parte o anseio do "Brasil Grande", ideário propagado pela Ditadura Civil-Militar (1964-1985). Somado a esse fator, pode-se considerar que apenas os setores detentores de capital, tanto o agroexportador quanto o financeiro, tiveram efetivos benefícios na promoção do que seria o "desenvolvimento" dessa região. Assim como outras grandes monoculturas, a soja também passou a dominar a paisagem da região. $\mathrm{Na}$ atualidade, essa política econômica é alvo de inúmeras críticas, especialmente porque grande parte do Centro-Oeste brasileiro repousa sobre uma das maiores reservas de água doce e potável do planeta: o "Aquífero Guarani".

No tempo presente, essa e outras práticas monoculturas servem-se dessas águas, tendendo em um futuro não muito longínquo a piorar, esgotar e sobremaneira inviabilizar a utilização por parte do ser humano de inúmeros mananciais de água outrora concebidos como potáveis. As comunidades tradicionais também foram e continuam sendo impactadas por esse modelo de desenvolvimento. 
Jussaramar da-Silva, Nataniél Dal-Moro. Geopolitics and west border: Dialogues with meira mattos and couto e silva

\section{Referências}

Abreu, S. de. (2001). Planejamento governamental: a SUDECO no espaço mato-grossense: contexto, propósitos e contradições. Tese (Doutorado de Geografia Humana) - Faculdade de Filosofia, Letras e Ciências Humanas, Universidade de São Paulo (USP), São Paulo. Alves, M. H. M. (2005). Estado e oposição no Brasil (1964-1984). Bauru: EDUSC.

Amaral, L. (1927). A mais linda viagem: um "raid" de vinte mil kilometros pelo interior brasileiro. São Paulo/Cayeiras/Rio de Janeiro: Melhoramentos de São Paulo.

Arruda, A. de. (1980). ESG: história de sua doutrina. São Paulo/Brasília: GRD/INL/MEC.

Assunção, V. N. F. de. (1999). O Satânico Doutor Go: a ideologia bonapartista de Golbery do Couto e Silva. Dissertação (Mestrado em Ciências Sociais) - Programa de Estudos Pós-Graduados em Ciências Sociais, Pontifícia Universidade Católica de São Paulo (PUC-SP), São Paulo.

Couto e Silva, G. do. (1967). Geopolítica do Brasil. Rio de Janeiro: José Olympio.

Couto e Silva, G. do. (1969). Interiorização, o grande tema em debate. Revista de Finanças Públicas, XXIX(279), 2-4.

Couto e Silva, G. do. (1981). Conjuntura política nacional: o poder executivo \& geopolítica do Brasil. 3. ed. Rio de Janeiro: José Olympio.

Fernandes, F. (2006). A Revolução burguesa no Brasil. Ensaio de interpretação sociológica. São Paulo: Globo.

Freitas, J. M. C. (1999). A Escola Geopolítica brasileira. Lisboa: Instituto Superior de Ciências Sociais e Políticas.

Hobsbawm, E. (1995). Era dos extremos: o breve século XX: 1914-1991. São Paulo: Companhia das Letras.

Ianni, O. (1979). A luta pela terra: história social da terra e da luta pela terra numa área da Amazônia. Petrópolis: Vozes.

Ianni, O. (1979). Colonização e contra-reforma agrária na Amazônia. Petrópolis: Vozes.

Ianni, O. (1979). Ditadura e agricultura: o desenvolvimento do capitalismo na Amazônia: 1964-1978. Rio de Janeiro: Civilização Brasileira. 
Joanoni Neto, V. (2007). Fronteiras da crença: ocupação do norte de Mato Grosso após 1970. Cuiabá: Carlini \& Caniato/UFMT.

Kohlhepp, G. (2002). Conflitos de interesse no ordenamento territorial da Amazônia brasileira. Estudos avançados, São Paulo, 16(45), 37-61.

Laino, D. (1979). Paraguai: fronteiras e penetração brasileira. São Paulo: Global.

Lenharo, A. (1985). Colonização e trabalho no Brasil: Amazônia, Nordeste, Centro-Oeste: anos 30. Campinas: UNICAMP.

Lenharo, A. (1989). Sacralização da política. (2. ed.) Campinas: UNICAMP/Papirus.

Meira Mattos, C. de. (1975). Brasil, geopolítica e destino. Rio de Janeiro: BIBLIEX.

Meira Mattos, C. de. (1977). A geopolítica e as projeções do poder. Rio de Janeiro: BIBLIEX.

Meira Mattos, C. de. (1980). Uma geopolítica pan-amazônica. Rio de Janeiro: BIBLIEX.

Meira Mattos, C. de. (1990). Geopolitica e teoria de fronteiras: fronteiras do Brasil. Rio de Janeiro: BIBLIEX.

Meira Mattos, C. de. (2002). Geopolítica e modernidade: a geopolítica brasileira. Rio de Janeiro: BIBLIEX.

Miyamoto, S. (1984). Geopolitica e autoritarismo: o caso brasileiro. Marília: UNESP.

Miyamoto, S. (1985). A geopolítica e o Brasil Potência. Marília: UNESP. Miyamoto, S. (1995). Geopolítica e poder no Brasil. Campinas: Papirus.

Moro, N. D. (2009). Representações da elite sobre o "povo comum" na cidade de Campo Grande (décadas de 1960-70). Fronteiras: revista do Programa de Pós-Graduação em História da UFGD, Dourados, 11 (20), 123-149.

Moro, N. D. (2014). Formas de conceber a terra no oeste do Brasil. História Revista: revista da Faculdade de História e do Programa de Pós-Graduação em História da UFG, Goiânia, 19 (1), 237-264. DOI: http://dx.doi.org/10.5216/hr.v19i1.30525

Olic, N. B. (1994). Geopolitica da América Latina. 8. ed. São Paulo: Moderna. Panosso Netto, A. (2002). Geopolítica, agricultores e madeireiros na frente oeste de colonização: o caso do norte de Mato Grosso. Campo Grande: UCDB. 
Rago, M. A. de P. (2008). José Ermírio de Moraes: a trajetória de um empresário nacional. São Paulo: Paz e Terra.

Silva, J. da. (2010). A Usina de Itaipu e a Operação Condor: o outro lado das relações bilaterais Brasil-Paraguai (1973-1988). Dissertação (Mestrado em História) - Programa de Estudos Pós-Graduados em História, Pontifícia Universidade Católica de São Paulo (PUC-SP), São Paulo.

Silva, J. da. (2013). A ação das Assessorias Especiais de Segurança e Informações da Usina Binacional de Itaipu no contexto das atividades de cooperação extrajudiciais no Cone Sul. Cordis: revista eletrônica de história social da cidade, PUC-SP, São Paulo, (11), 219-251.

Tota, A. P. (2000). O imperialismo sedutor: a americanização do Brasil na época da Segunda Guerra. São Paulo: Companhia das Letras.

Turner, S. (2008). Queime antes de ler: presidentes, diretores da CIA e espionagem internacional. Rio de Janeiro/São Paulo: Record.

Vizentini, P. F. (2003). Relações internacionais do Brasil: de Vargas a Lula. São Paulo: Perseu Abramo.

Zago, L. G. (2007). Fronteira e Segurança Nacional no Extremo Oeste Paranaense: um estudo do Município de Marechal Cândido Rondon. Dissertação (Mestrado em História) - Programa de Pós-Graduação em História, Instituto de Filosofia e Ciências Humanas, Universidade de Passo Fundo (UPF), Passo Fundo. 